\title{
Decompressive Craniectomy for Traumatic Brain Injury: In-hospital Mortality-Associated Factors
}

\author{
Fernando Celi ${ }^{1}$ Giancarlo Saal-Zapata ${ }^{2,3, \odot}$ \\ ${ }^{1}$ Department of Neurosurgery, Hospital de Emergencias José \\ Casimiro Ulloa, Miraflores, Lima, Perú \\ ${ }^{2}$ Department of Neurosurgery, Hospital Nacional Guillermo \\ Almenara Irigoyen - EsSalud, La Victoria, Lima, Perú \\ ${ }^{3}$ Clínica Angloamericana, San Isidro, Lima, Perú
}

\author{
Address for correspondence Giancarlo Saal-Zapata, MD, \\ Grau Avenue 800, La Victoria, Lima 13, Perú \\ (e-mail: gian_carlo1987@hotmail.com,gsaal1987@gmail.com).
}

J Neurosci Rural Pract 2020;11:601-608

\begin{abstract}
Keywords

- decompressive craniectomy

- intracranial pressure

- intracranial hypertension

- traumatic brain injury
\end{abstract}

Objective Determine predictors of in-hospital mortality in patients with severe traumatic brain injury (TBI) who underwent decompressive craniectomy.

Materials and Methods This retrospective study reviewed consecutive patients who underwent a decompressive craniectomy between March 2017 and March 2020 at our institution, and analyzed clinical characteristics, brain tomographic images, surgical details and morbimortality associated with this procedure.

Results Thirty-three (30 unilateral and 3 bifrontal) decompressive craniectomies were performed, of which 27 patients were male (81.8\%). The mean age was 52.18 years, the mean Glasgow coma scale (GCS) score at admission was 9, and 24 patients had anisocoria (72.7\%). Falls were the principal cause of the trauma (51.5\%), the mean anterior-posterior diameter (APD) of the bone flap in unilateral cases was $106.81 \mathrm{~mm}$ (standard deviation [SD] 20.42) and 16 patients (53.3\%) underwent a right-sided hemicraniectomy. The temporal bone enlargement was done in 20 cases $(66.7 \%)$, the mean time of surgery was 2 hours and 27 minutes, the skull flap was preserved in the subcutaneous layer in 29 cases (87.8\%), the mean of blood loss was $636.36 \mathrm{~mL}$,and in-hospital mortality was $12 \%$. Univariate analysis found differences between the APD diameter ( $120.3 \mathrm{~mm}$ vs. $85.3 \mathrm{~mm} ; p=0.003)$ and the presence of midline shift $>5 \mathrm{~mm}$ $(p=0.033)$.

Conclusion The size of the skull flap and the presence of midline shift $>5 \mathrm{~mm}$ were predictors of mortality. In the absence of intercranial pressure (ICP) monitoring, clinical and radiological criteria are mandatory to perform a decompressive craniectomy.

\section{Introduction}

Traumatic brain injury (TBI) is a serious pathology that conditions an increase in morbidity and mortality, with more than 50,000 deaths annually in developed countries. ${ }^{1}$ Secondary damage due to cerebral edema, contusions, subdural hematoma (SDH), epidural hematoma(EDH), and others lead to a progressive increase in intracranial pressure (ICP), with consequent alteration in the brain compliance., ${ }^{2,3}$

Intracranial hypertension is related to a higher prevalence of disability and death if not treated. Guidelines propose a step-wise treatment to control ICP, but when intracranial hypertension is refractory to medical or first-tier management, decompressive craniectomy (DC) is the treatment of choice. ${ }^{4}$ Randomized controlled trials and guidelines have evaluated the benefits of DC over optimal medical treatment in cases of TBI with intracranial hypertension and recommend this procedure to improve neurologic outcomes and lower mortality rates. ${ }^{4-7}$ Few studies in our country have issued this problem, ${ }^{89}$ so we aimed to evaluate our experience of consecutive patients with severe TBI who underwent DC in our institution and analyze in-hospital mortality-associated factors. 


\section{Materials and Methods}

\section{Patient Selection}

Between March 2017 and March 2020, 33 consecutive patients with the diagnosis of severe TBI underwent 33 decompressive craniectomies at the Hospital de Emergencias José Casimiro Ulloa from Lima, Perú. Clinical charts and brain CT scans were used to analyze demographics, clinical characteristics, tomographic findings, surgical details, procedure-related complications, and mortality associated with the procedure. The study was approved by the ethics committee of the hospital.

Demographics and clinical characteristics included age, sex, the mechanism of trauma, the presence of anisocoria, and the Glasgow coma scale (GCS) score at admission. The tomographic findings analyzed were the presence of acute SDHs and EDHs, midline shift $>5 \mathrm{~mm}$, traumatic subarachnoid hemorrhage (SAH), cerebral contusions, skull fracture, and the Marshall classification. Surgical details included the type of craniectomy, the side of the craniectomy in unilateral cases, the anterior-posterior diameter (APD) in unilateral craniectomies, temporal bone removal (enlargement toward the skull base or zygomatic arch with drill or rongeur), blood loss, the subcutaneous layer placement of the bone flap, and the time of surgery.

Unilateral or bifrontal craniectomies were performed according to the type and location of the lesion and CT scans. ICP monitoring was not performed in any of the cases. For unilateral DC, a question mark incision and a frontotemporoparietal bone flap with duroplasty was done. In cases of a bifrontal DC, a bicoronal incision with a flap from the frontal bone to the coronal suture with duroplasty was performed. All the procedures were catalogued as primary DC, and ICP monitoring was not performed.

\section{Statistical Analysis}

Categorical variables were expressed as percentages, and numerical variables were expressed as means \pm SD. Differences between numerical variables were analyzed with t-student or Mann-Whitney tests, depending on its distribution, and the Fisher's test was employed for categorical variables. A pvalue $<0.05$ was considered statistically significant. The software Stata v14.0 (StataCorp, College Station, Texas) was used for the analysis.

\section{Results}

\section{Population Characteristics}

Thirty-three decompressive craniectomies were analyzed, of which 30 were unilateral and three were bifrontal craniectomies. Males represented $81.8 \%$ of the cases and the mean age was $52.2 \pm 20.1$ years (range 22 to 85 years). The principal mechanism of trauma wasfalls (51.5\%), traffic accidents (36.4\%), and hit by an object (12.1\%). The mean GCS score at admission was 9, and 24 patients (72.7\%) presented anisocoria at admission. Fifteen patients had a GCS $\leq 8$ points $(45.5 \%)$ (-Table 1).

\section{Tomographic Findings}

The predominant tomographic findings were the presence of midline shift $>5 \mathrm{~mm}$ and a SDH in $90.1 \%$ and $87.9 \%$ of the cases, respectively.

Traumatic SAH, brain contusions and skull fractures were observed in $57.6 \%, 51.5 \%$ and $36.4 \%$ of the cases, respectively. The presence of an epidural hematoma was found in $6.1 \%$ of the cases.

All the patients were classified according to the Marshall Classification and all of them presented a score greater than 3 . Thirteen patients were catalogued as a Marshal grade 3-4 and 20 patients as a Marshal 6. Three out of fourpatients who died were catalogued as Marshall 6 (75\%) (-Table 2).

\section{Surgical Procedure Characteristics}

Sixteen patients (53.3\%) underwent a right-sided craniectomy and the mean APD of the unilateral craniectomy was $106.8 \mathrm{~mm} \pm 20.4 \mathrm{~mm}$ (range 70.26 to $166.42 \mathrm{~mm}$ ), the temporal bone was removed in 20 patients $(66.3 \%)$ of the unilateral cases, the skull flap was preserved in the subcutaneous layer in 29 patients (87.8\%), and the average time of the surgery was 2 hours and 27 minutes (-Figs. 1 and 2 ). The mean blood loss was $636.4 \mathrm{~mL} \pm 375.1 \mathrm{~mL}$.

\section{Complications and Mortality}

Four patients (12\%) presented cerebrospinal fluid (CSF) fistulas and three patients (9\%) developed subcutaneous abdominal infections. The in-hospital mortality rate was four patients (12\%).

\section{Univariate Analysis}

When comparing both groups, there were no differences among the covariates, except for the mean APD of the skull flap, which was larger in patients who survived $(120.3 \mathrm{~mm}$ vs. $85.3 \mathrm{~mm} ; p=0.003)$ and the presence of midline shift $>5 \mathrm{~mm}(p=0.033)$ (-Table 3).

\section{Discussion}

Decompressive craniectomy is a live-saving procedure in cases of TBI with intracranial hypertension. In this study, we report an in-hospital mortality rate of $12 \%$, and mortalityassociated factors found were the APD of the skull flap and the presence of midline shift greater than $5 \mathrm{~mm}$.

Regarding the optimal management of TBI, guidelines recommend medical treatment with first-tier management, followed by the second-tier management, which includes DC, among other options, such as barbiturate coma. ${ }^{10}$ Depending on the presence of ICP monitoring, if the DC is performed once, the diagnosis of TBI with intracranial hypertension is made; then, the procedure is termed primary DC and is usually performed within the first 24 hours. When ICP monitoring is available and intracranial hypertension is refractory to medical management, then the procedure is termed secondary DC. Current indications for DC are as follows: comatose patients with the presence of an acute SDH, severe brain swelling, midline shift $>5 \mathrm{~mm}$,absence of basal cisterns due 


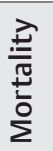

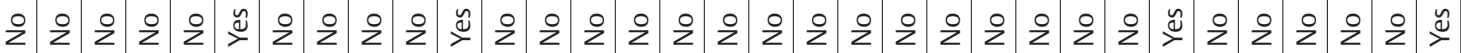

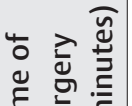

言 站

$气$

¿

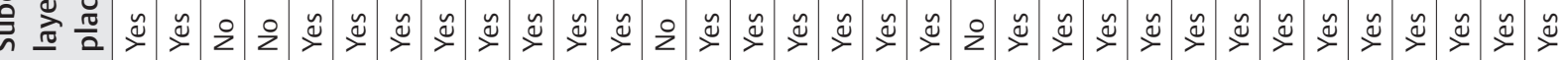

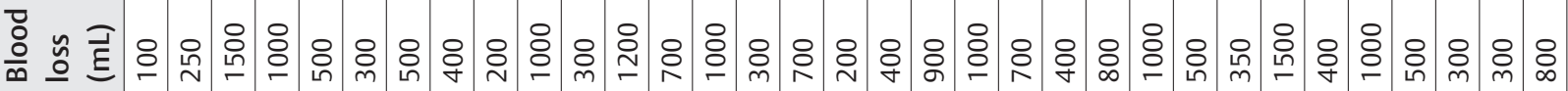

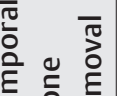

焉

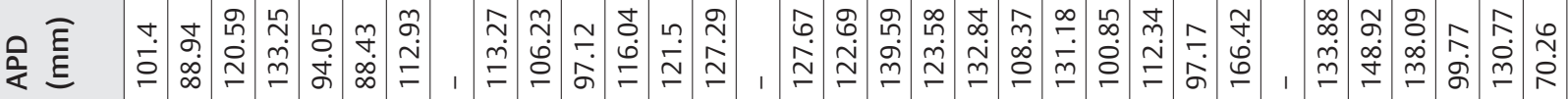

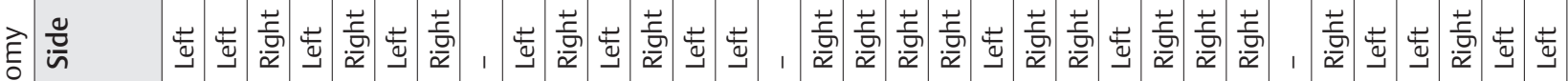

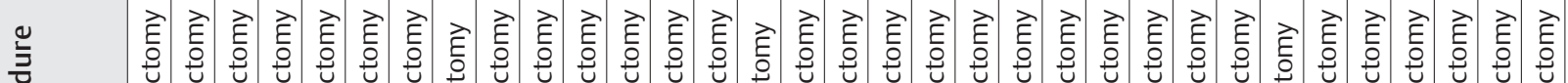

जे

竞

है तु

ำ 즌

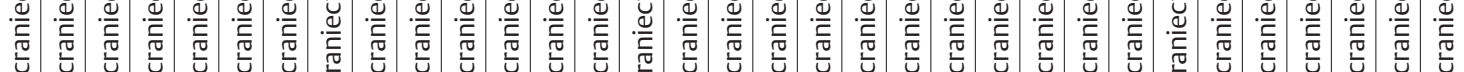

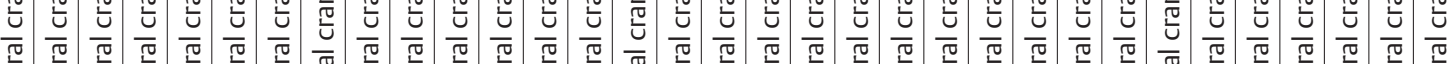

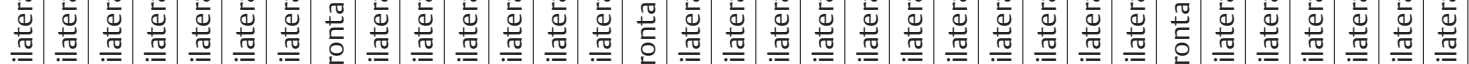

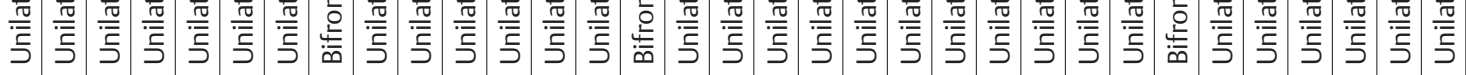

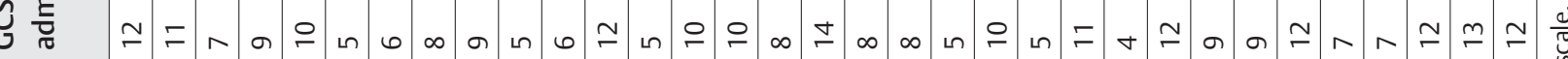
葍 竞

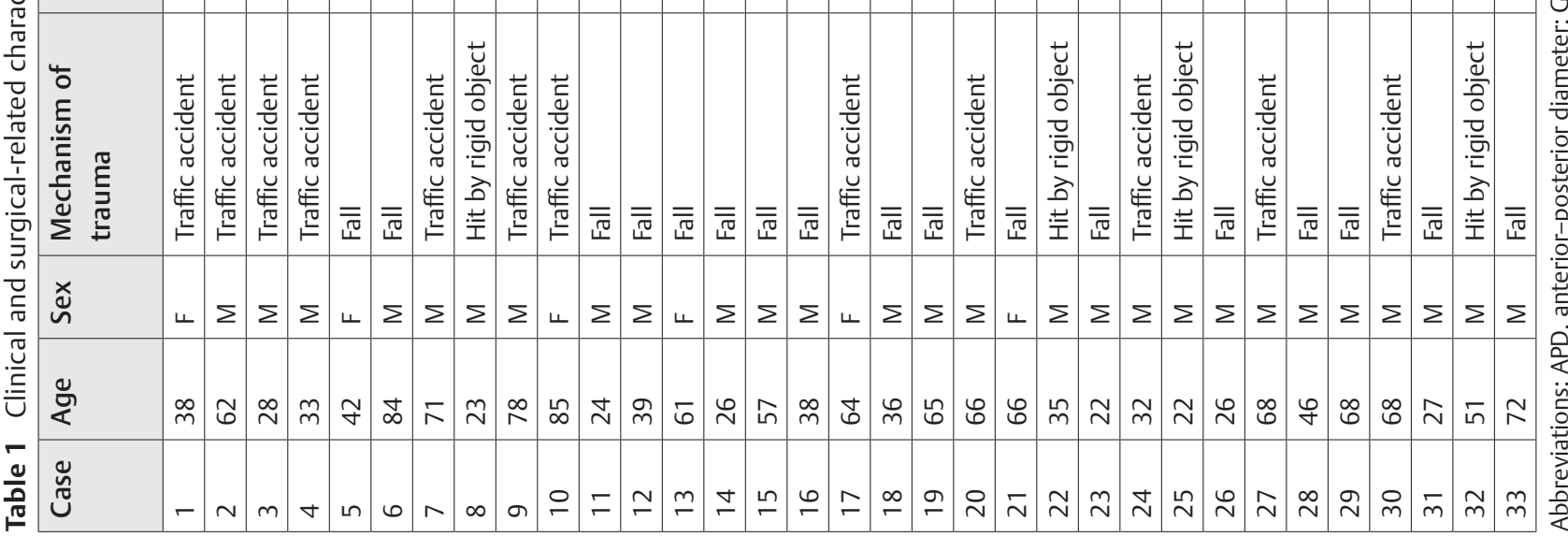


Table 2 Tomographic characteristics of patients who underwent decompressive craniectomy

\begin{tabular}{|c|c|c|c|c|c|c|c|}
\hline Patient & $\begin{array}{l}\text { Marshall } \\
\text { classification }\end{array}$ & SDH & EDH & $\begin{array}{l}\text { Midline } \\
\text { shift }\end{array}$ & $\begin{array}{l}\text { Cerebral } \\
\text { contusion }\end{array}$ & Traumatic SAH & Skull fracture \\
\hline 1 & 4 & + & - & + & - & + & - \\
\hline 2 & 6 & - & + & + & + & - & - \\
\hline 3 & 3 & + & - & + & - & - & + \\
\hline 4 & 3 & + & - & + & - & + & + \\
\hline 5 & 3 & + & - & + & - & + & - \\
\hline 6 & 6 & + & - & + & - & - & - \\
\hline 7 & 6 & + & - & + & + & - & - \\
\hline 8 & 6 & + & - & + & - & - & - \\
\hline 9 & 6 & + & - & + & + & + & - \\
\hline 10 & 6 & + & - & + & + & - & - \\
\hline 11 & 3 & + & - & + & - & + & - \\
\hline 12 & 6 & - & + & + & - & - & - \\
\hline 13 & 6 & + & - & + & + & + & - \\
\hline 14 & 4 & + & - & + & + & + & + \\
\hline 15 & 6 & - & - & + & + & + & + \\
\hline 16 & 6 & + & - & + & + & + & - \\
\hline 17 & 6 & + & - & + & + & + & + \\
\hline 18 & 6 & + & - & + & + & + & + \\
\hline 19 & 6 & + & - & + & + & + & - \\
\hline 20 & 6 & + & - & + & - & + & + \\
\hline 21 & 3 & + & - & + & + & - & + \\
\hline 22 & 6 & + & - & - & + & + & + \\
\hline 23 & 6 & + & - & + & + & + & - \\
\hline 24 & 4 & + & - & + & - & + & - \\
\hline 25 & 3 & + & - & + & - & - & - \\
\hline 26 & 6 & + & - & + & - & + & + \\
\hline 27 & 6 & - & - & - & + & + & + \\
\hline 28 & 6 & + & - & + & + & - & + \\
\hline 29 & 4 & + & - & + & - & - & - \\
\hline 30 & 4 & + & - & + & - & - & - \\
\hline 31 & 4 & + & - & + & - & - & - \\
\hline 32 & 4 & + & - & + & - & - & - \\
\hline 33 & 6 & + & - & - & + & + & - \\
\hline
\end{tabular}

Abbreviations: $\mathrm{EDH}$, epidural hematoma; SAH, subarachnoid hemorrhage; SDH, subdural hematoma

to a parenchymal hemorrhage or brain contusions with or without surrounding edema, and the presence of anisocoria.

Randomized controlled trials sought to determine the benefits of performing DC in patients with TBI. In the DECRA trial, bifrontal decompressive craniectomy was associated with unfavorable outcomes when compared with medical therapy (70\% vs. 51\%) and no significant differences in mortality rates between surgical and medical groups were found at 6 months (19\% vs. 18\%). ${ }^{5,11}$ In the RESCUEicp trial, decompressive craniectomy in patients with TBI and refractory 

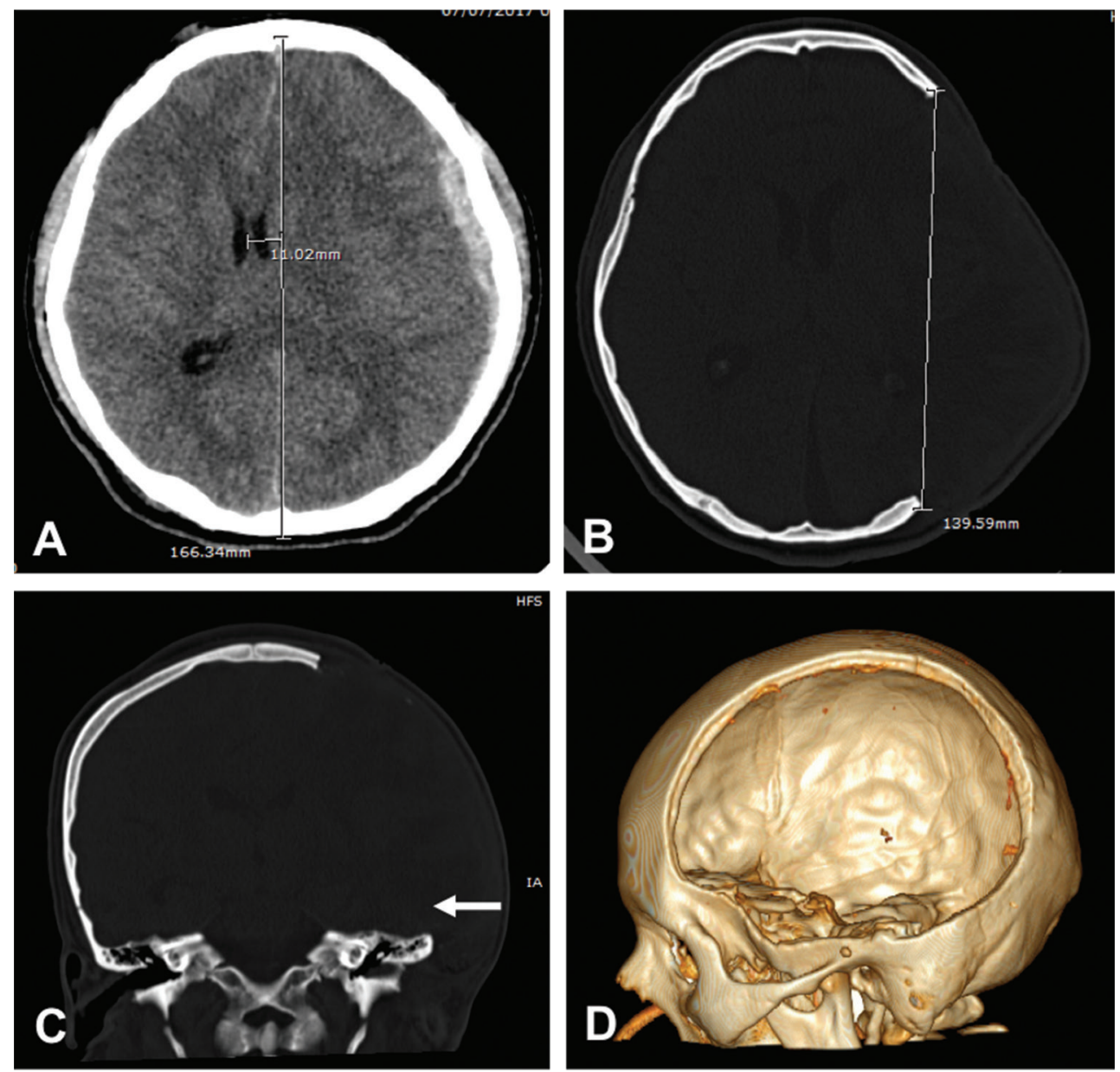

Fig. 1 (A) Brain CT scan shows an acute subdural hematoma with midline shift. (B, C) Postoperative CT scan showing the diameter of the craniectomy with resection of temporal bone (arrow). (D) 3D reconstruction showing the defect.

intracranial hypertension resulted in lower mortality and higher rates of severe disability at 6 months. A favorable outcome at 6 months (better on the GOSE) with surgery was obtained $(42.8 \%$ vs. $34.6 \%, p=0.12)$ and mortality rates were significantly lower with surgery $(26.9 \% \text { vs.48.9\% })^{6}$ The RESCUE-ASDH trial aims to address whether primary DC or craniotomy are the best strategies for patients with severe TBI who undergo evacuation of an acute SDH. Nevertheless, results from this trial are not yet available. ${ }^{12}$ In addition, a Chinese trial found lower mortality rates (26.2\% vs.35.1\%) and higher favorable outcomes (39.8\% vs.28.6\%) in patients who underwent a standard DC $(12 \times 15 \mathrm{~cm}$ flap) compared with limited DC $\left(6 \times 8 \mathrm{~cm}\right.$ flap).$^{13}$ Technical nuances to perform a DC have been reported. ${ }^{14}$ The AP diameters of bone flaps range from 12 to $15 \mathrm{~cm}$ in unilateral craniectomies; $1^{5,16}$ nevertheless, the ideal bone flap diameter should be larger than $15 \mathrm{~cm}$ to achieve an adequate decompression. ${ }^{17,18}$

Regarding the management of TBI in Perú, a developing country in South America, scarce publications were found. ${ }^{8,9,19}$ One descriptive study in a public hospital evaluated 76 patients who underwent surgery due to TBI. Sixteen patients (21.1\%) underwent DC in its two modalities (unilateral or bifrontal), ICP monitoring was used in 12 cases (15.8\%), and the mortality rate was 9 patients (11.8\%). ${ }^{8}$

Despite the small sample, our analysis yielded important results. The size of the bone flap is an important predictor of mortality and good outcomes, as shown in previous studies. ${ }^{14,15,17,18}$ The ideal APD to relief the high ICP is $15 \mathrm{~cm}$. However, four patients had an average diameter of $85.3 \mathrm{~mm}$ and all of them died. Patients were classified according to the Marshall tomographic scale and all were catalogued as Marshall $\geq 3$. Of the four dead patients, three had a Marshall 6 type of lesion. In-hospital mortality rates in our series is relatively lower compared with previous studies, ${ }^{20,21}$ despite the lack of ICP monitoring. This could be explained because $55 \%$ of our series presented a GCS score $>8$ points on admission and the issue that $100 \%$ of the surgeries were primary DC. A combination of tomographic findings wasfound in the same patient. Midline shift was present in $90.1 \%$ of the cases, followed by the presence of a SDH in $87.9 \%$ of the cases.

The decision to perform a smaller or larger craniectomy was based on the surgeon's decision and radiological findings. In the case of a smaller craniectomy (mean $85 \mathrm{~mm}$ in 

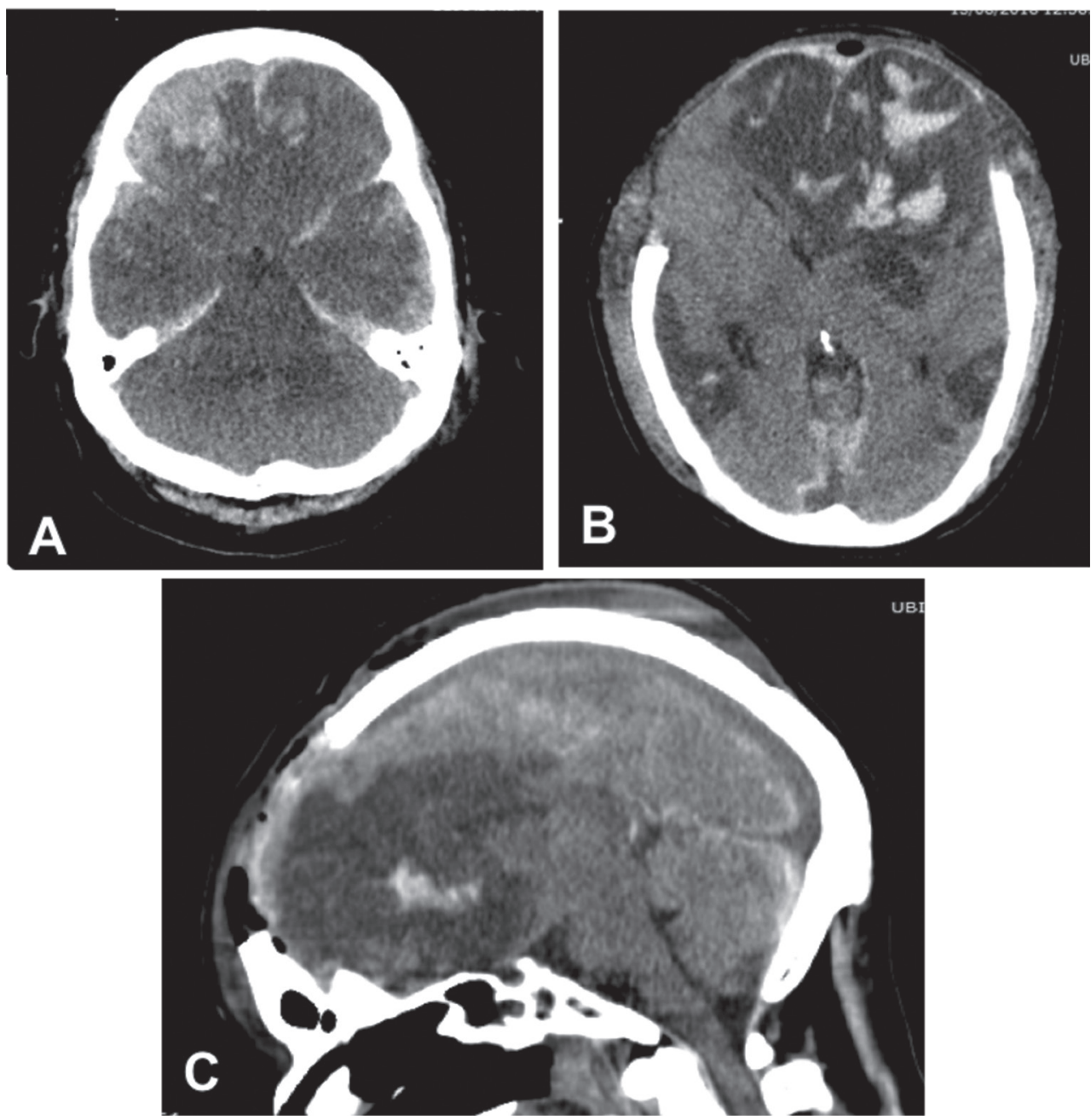

Fig. 2 (A) Brain CT scan showing an acute subdural hematoma with frontal contusions and severe edema. (B-D) Postoperative bifrontal decompressive craniectomy.

APD), the total evacuation of the hematoma was followed by optimal medical management. We have to take into consideration the fact that all the procedures were primary DC, two of four patients who died had a midline shift $>5 \mathrm{~mm}$, and one patient underwent temporal bone enlargement. In addition, in this particular subgroup of patients when the surgery was done, the brain was not seriously edematous after hematoma evacuation.

According to the literature, factors associated withmortality are age, the low-GCS score at admission, the size of the craniectomy, effacement of basal cisterns, and severe midline shift. ${ }^{13,16,22-24}$ Unfavorable outcomes reported were low-GCS scores on admission, postoperative hydrocephalus, tracheostomy, sphenoid fractures, and unchanged ICP. ${ }^{21,25,26}$

DC-relatedmortality rates ranged from 12 to $55 \%$. $^{16,20-22,24-27}$ In-hospital mortality rates ranged between 32 to $55 \%, 20,21,26$ whereas 30-day mortality rates ranged from 12 to $28.3 \%{ }^{16,22,24,27}$ Laghari et al reported an in-hospital mortality rate of $25 \%$ at 3 months in their series. In addition, Khalili reported a mortality rate of $40.8 \%$ at 1 -year follow-up.

Regarding procedure-related complications, our rate of CSF fistulas was high compared with the reported in the literature (6\% vs.12\%). ${ }^{18}$ Postoperative infection rates such as abdominal infections represent around $10 \%$, similar to our $9 \%$ abdominal infection rate. ${ }^{18}$

This study has limitations. The small sample and the retrospective design did not allow to draw more robust statistical associations. None of the patients had ICP monitoring before, during, or after the surgery. Postoperative clinical outcomes were not assessed. Our institution is an emergency hospital where potentially surgical patients undergo emergent surgeries, and after their recovery, they are discharged to other institutions or to their homes. For this reason, follow-up was not feasible. Further investigations should be performed in developing countries regarding trauma and its surgical management.

\section{Conclusions}

In our analysis, the mean diameter of the bone flap in unilateral craniectomies and the midline shift were associated within-hospital mortality. In centers without ICP monitoring, primary decompressive craniectomy should be performed according to clinical and radiological criteria. 
Table 3 Univariate analysis of mortality-associated factors following decompressive craniectomy

\begin{tabular}{|c|c|c|c|}
\hline Variable & $\begin{array}{l}\text { Alive } \\
n=29\end{array}$ & $\begin{array}{l}\text { Dead } \\
n=4\end{array}$ & $p$-Value \\
\hline Age & $47.4 \pm 19$ & $62 \pm 20.1$ & 0.178 \\
\hline Sex & & & 0.429 \\
\hline Male & $23(85.2)$ & $4(14.8)$ & \\
\hline Female & $6(100)$ & $0(0)$ & \\
\hline Trauma mechanism & & & 0.781 \\
\hline Fall & $14(82.4)$ & $3(17.6)$ & \\
\hline Traffic accident & $11(91.7)$ & $1(8.3)$ & \\
\hline Hit by object & $4(100)$ & $0(0)$ & \\
\hline Presence of anisocoria & $23(95.8)$ & $1(4.2)$ & 0.052 \\
\hline Glasgow at admission & $9 \pm 2.8$ & $8 \pm 3.2$ & 0.537 \\
\hline \multicolumn{4}{|c|}{ Surgical characteristics } \\
\hline Type of surgery & & & 0.330 \\
\hline Unilateral craniectomy & $27(90)$ & $3(10)$ & \\
\hline Bilateral craniectomy & $2(66.7)$ & $1(33.3)$ & \\
\hline Side of the craniectomy & & & 0.09 \\
\hline Right & $16(100)$ & $0(0)$ & \\
\hline Left & $11(78.6)$ & $3(21.4)$ & \\
\hline $\begin{array}{l}\text { APD of craniectomy } \\
\text { (unilateral cases) }\end{array}$ & $120.3 \pm 18$ & $85.3 \pm 13.7$ & 0.003 \\
\hline Removal of temporal bone & $19(95)$ & $1(5)$ & 0.251 \\
\hline Blood loss* & $500(100-1500)$ & $550(300-1500)$ & 0.956 \\
\hline SCL placement of bone flap & $25(86.2)$ & $4(13.8)$ & 0.580 \\
\hline Time of surgery & $150(90-255)$ & $120(70-235)$ & 0.375 \\
\hline \multicolumn{4}{|c|}{ Tomographic findings } \\
\hline Marshall at admission & & & 0.481 \\
\hline Grade 3-4 & $12(92.3)$ & $1(7.7)$ & \\
\hline Grade 6 & $17(85)$ & $3(15)$ & \\
\hline Presence of subdural hematoma & $26(89.7)$ & $3(10.3)$ & 0.420 \\
\hline Presence of epidural hematoma & $2(100)$ & $0(0)$ & 0.769 \\
\hline $\begin{array}{l}\text { Presence of midline shift } \\
>5 \mathrm{~mm}\end{array}$ & $28(93.3)$ & $2(6.7)$ & 0.033 \\
\hline Presence of cerebral contusion & $15(88.2)$ & $2(11.8)$ & 0.676 \\
\hline $\begin{array}{l}\text { Presence of traumatic } \\
\text { subarachnoid hemorrhage }\end{array}$ & $16(84.2)$ & $3(15.8)$ & 0.426 \\
\hline Presence of cranial fracture & $11(91.7)$ & $1(8.3)$ & 0.536 \\
\hline
\end{tabular}

aMann-Whitney: median and ranges

\section{Conflict of Interest}

None declared.

\section{References}

1 Faul M, Coronado V. Epidemiology of traumatic brain injury. In: Grafman J, Salazar A, eds. Handbook of Clinical Neurology, Vol. 127 (3rd series) Traumatic Brain Injury, Part IJ. Elsevier; 2015:3-13
2 Robinson JD. Management of refractory intracranial pressure. Crit Care Nurs Clin North Am 2016;28(1):67-75

3 Smith M, Servadei F, Hutchinson PJ. What is new in decompressive craniectomy in neurological emergencies: the good, the bad and the ugly. Intensive Care Med 2020;46(5):1023-1026

4 Carney N, Totten AM, O'Reilly C, et al. Guidelines for the management of severe traumatic brain injury, fourth edition. Neurosurgery 2017;80(1):6-15

5 Cooper DJ, Rosenfeld JV, Murray L, et al; DECRA Trial InvestigatorsAustralian and New Zealand Intensive Care Society 
Clinical Trials Group. Decompressive craniectomy in diffuse traumatic brain injury. N Engl J Med 2011;364(16):1493-1502

6 Hutchinson PJ, Kolias AG, Timofeev IS, et al; RESCUEicp Trial Collaborators. Trial of decompressive craniectomy for traumatic intracranial hypertension. N Engl J Med 2016;375(12): $1119-1130$

7 Sahuquillo J, Dennis JA. Decompressive craniectomy for the treatment of high intracranial pressure in closed traumatic brain injury. Cochrane Database Syst Rev 2019; 12(12):CD003983

8 Flores J, Polo de la Piedra C, López J, Pascual R. Tratamiento quirúrgico del traumatismoencéfalocraneano: Resultadoen una serie de 76 pacientes. Rev Peru Neurocir 2010;5(2):5-10

9 Cam Páucar JL. Manejo inicial del paciente con trauma craneoencefálico e hipertensiónendocraneanaaguda. Actual Med Peru 2011;28:39-45

10 Rangel-Castilla L, Gopinath S, Robertson CS. Management of intracranial hypertension. Neurol Clin 2008;26(2):521-541, x

11 Honeybul S, Ho KM, Lind CRP. What can be learned from the DECRA study. World Neurosurg 2013;79(1):159-161

12 Kolias AG, Viaroli E, Rubiano AM, et al. The current status of decompressive craniectomy in traumatic brain injury. Curr Trauma Rep 2018;4(4):326-332

13 Jiang J-Y, Xu W, Li W-P, et al. Efficacy of standard trauma craniectomy for refractory intracranial hypertension with severe traumatic brain injury: a multicenter, prospective, randomized controlled study. J Neurotrauma 2005;22(6):623-628

14 Huang X, Wen L. Technical considerations in decompressive craniectomy in the treatment of traumatic brain injury. Int J Med Sci 2010;7(6):385-390

15 Ho M-Y, Tseng W-L, Xiao F, Estimation of the craniectomy surface area by using post-operative images. International Journal of Biomedical Imaging 2018:1-8. Doi: 10.1155/2018/5237693

16 Gouello G, Hamel O, Asehnoune K, Bord E, Robert R, Buffenoir K, Study of the long-term results of decompressive craniectomy after severe traumatic brain injury based on a series of 60 consecutive cases. In: Butt WW, Schaller B, eds. 2014207585

17 Moon JW, Hyun DK. Decompressive craniectomy in traumatic brain injury: a review article. Korean J Neurotrauma 2017; 13(1):1-8
18 Gopalakrishnan MS, Shanbhag NC, Shukla DP, Konar SK, Bhat DI, Devi BI. Complications of decompressive craniectomy. Front Neurol 2018;9:977

19 Guillén-Pinto D, Zea-Vera A, Guillén-Mendoza D, et al. Traumatismoencefalocraneanoenniñosatendidosen un hospital nacional de Lima, Perú 2004-2011. Rev Peru Med Exp Salud Publica 2013;30(4):630-634

20 Howard JL, Cipolle MD, Anderson M, et al. Outcome after decompressive craniectomy for the treatment of severe traumatic brain injury. J Trauma 2008;65(2):380-385, discussion 385-386

21 Williams RF, Magnotti LJ, Croce MA, et al. Impact of decompressive craniectomy on functional outcome after severe traumatic brain injury. J Trauma 2009;66(6):1570-1574, discussion 1574-1576

22 Huang Y-H, Lee T-C, Lee T-H, Liao C-C, Sheehan J, Kwan A-L. Thirty-day mortality in traumatically brain-injured patients undergoing decompressive craniectomy. J Neurosurg 2013;118(6):1329-1335

23 Sedney CL, Julien T, Manon J, Wilson A. The effect of craniectomy size on mortality, outcome, and complications after decompressive craniectomy at a rural trauma center. J Neurosci Rural Pract 2014;5(3):212-217

24 Ogunlade J, Elia C, Duong J, et al. Severe traumatic brain injury requiring surgical decompression in the young adult: factors influencing morbidity and mortality - a retrospective analysis. Cureus 2018;10(7):e3042-e3042

25 Khalili H, Niakan A, Ghaffarpasand F, Kiani A, Behjat R. Outcome determinants of decompressive craniectomy in patients with traumatic brain injury:a single center experience from southern Iran. Bull Emerg Trauma 2017;5(3):190-196

26 Laghari AA, Bari ME, Waqas M, Ahmed SI, Nathani KR, Moazzam W. Outcome of decompressive craniectomy in traumatic closed head injury. Asian J Neurosurg 2018;13(4): 1053-1056

27 Qiu W, Guo C, Shen H, et al. Effects of unilateral decompressive craniectomy on patients with unilateral acute post-traumatic brain swelling after severe traumatic brain injury. Crit Care 2009;13(6):R185-R185 